\title{
Applying HF and VHF/UHF Partial Discharge Detection for Distribution Transformer
}

\author{
Sakda Maneerot, Masaaki Kando and Norasage Pattanadech* \\ Department of Electrical Engineering, Faculty of Engineering, King Mongkut's \\ Institute of Technology Ladkrabang, Chalongkrung Road, Ladkrabang, Bangkok \\ 10520, Thailand \\ E-mail: sakda@teslapower.co.th; masaaki.ka@kmitl.ac.th; \\ norasage.pa@kmitl.ac.th \\ ${ }^{*}$ Corresponding Author
}

Received 1 May 2020; Accepted 14 May 2020;

Publication 07 August 2020

\begin{abstract}
This paper represents application of high frequency (HF) and very high frequency/ultrahigh frequency (VHF/UHF) partial discharge (PD) detection for a distribution transformer. A capacitive sensor is used to detect the HF electric field caused by charge transfer inside oil-paper insulation due to $\mathrm{PD}$ at the defect site, and an electromagnetic sensor or antenna is used for detecting electromagnetic PD transients in the air outside the investigated transformer in the near-field region. Three types of artificial PD sources in air and insulating liquid, which are corona discharge, surface discharge and air void discharge in pressboard, were investigated. Three identical distribution transformers were rated at $22 \mathrm{kV}, 400 \mathrm{~V}$ and $50 \mathrm{kVA}$, and were designed and constructed. The first transformer was filled with mineral oil, the second was filled with natural ester and the third was filled with palm oil. The PD generated by the air-filled voids in the insulating papers and pressboards of these transformers with five different conditions were investigated, i.e., non-impregnated paper, impregnated paper for 3 hours, 6 hours, 9 hours and 12 hours. The impregnation process was done with $65^{\circ} \mathrm{C}$ liquid temperature, and the pressure in the oven was around 5 mbar. From the experimental results, it can be concluded that the electromagnetic PD transients radiated
\end{abstract}

Journal of Mobile Multimedia, Vol. 15_4, 357-376.

doi: 10.13052/jmm1550-4646.1545

(C) 2020 River Publishers 
from the corona discharge of both high-voltage (HV) and low-voltage sides in the air are in the VHF range, and surface discharge frequency is extended up to the UHF range. For the PD in the insulating liquid, the phase resolved PD (PRPD) pattern in the HF range is a valuable tool to characterize the PD sources. The PD in an air-filled void inside the insulating paper of the mineral oil transformer is obviously different compared with those of the natural ester transformer and the palm oil transformer. For the manufacturing of distribution transformers in this research, it is found that after the paper insulation is dried out, the impregnation process for a period of 9 hours is suitable for improving the oil-paper insulation with an acceptable PD level. This paper is the cross-field application by applying the antenna and communication theory for detecting the discharge problems in HV equipment.

Keywords: Capacitive sensor, antenna, electromagnetic transients, partial discharge, distribution transformer.

\section{Introduction}

Partial discharge (PD) is an incomplete electrical breakdown process occurring during insulation defects in an insulation system. The PD source generates various physical characteristic signals, i.e., light, acoustic and electromagnetic wave emission as well as a chemical by-product. The PD signal can be detected by a suitable sensor, both offline and online measurement. In general, the PD measurement technique via the electrical signal is the effective test technique applied for verifying the insulation system of an high-voltage (HV) apparatus. The PD signal and PD amplitude in time and frequency domain are valuable parameters that are used to investigate the symptom of insulation degradation for assessing the insulation condition [1-5].

Distribution transformers are the most critical equipment, which play a significant role in transmission and distribution networks. The insulation of a transformer is the weakest point in the transformer compared with other materials used, i.e., copper and iron core. It is known that the lifetime of the HV equipment strongly depends on the condition of the insulation utilized. Therefore, the study and investigation of the insulation characteristics of the transformer are very important.

The PD commonly occurs at defect insulations inside and outside the transformers. The discharge pulse characteristics have a wide frequency range. Discharge amplitude, pulse shape and the repeat occurrence of PD magnitude are investigated to analyse the severity of the PD. 


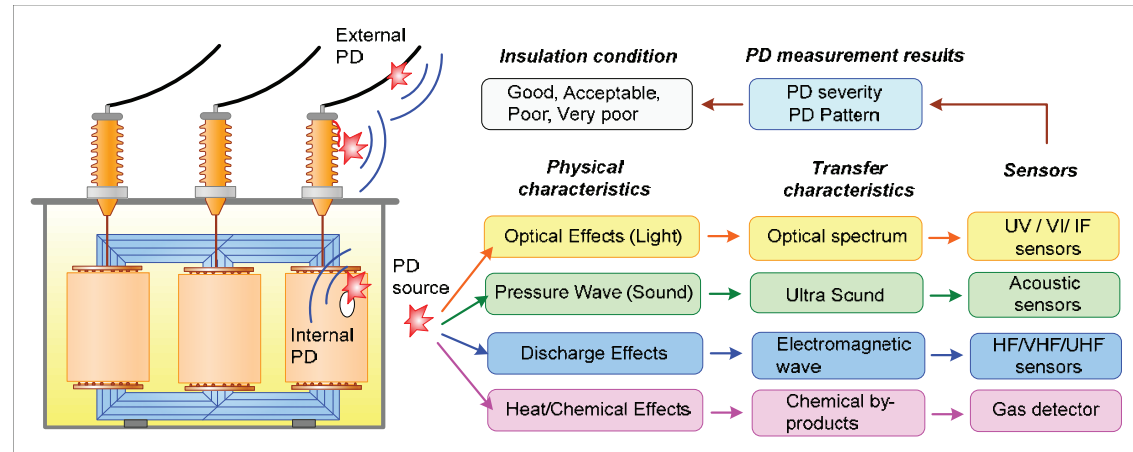

Figure 1 Physical PD characteristics and PD sensors.

Nowadays, natural ester is utilized as the alternative insulating liquid in the transformers, especially the distribution transformer owing to high electric breakdown strength, higher flash and fire points and biodegradation characteristics. The application of natural ester is still fast growing up in the transformer industry. Besides, palm oil, as one type of ester, has been proposed to use in the transformer also due to the low price and being good enough with the desired dielectric function. However, there are few pieces of research about the dielectric characteristics of natural ester and palm oil application in the transformers. Therefore, it is needed to investigate such characteristics as proposed in this paper.

In this paper, the PD signal characteristics obtained from different PD sources, which are corona discharges, surface discharges, discharges in airfilled voids of insulating paper, as well as discharge in air-filled voids of nonimpregnated winding insulation of distribution transformer are investigated by applying the PD measurement techniques.

The finding in this research work will fulfil the knowledge of the PD signal with reference to both the electric field and electromagnetic field characteristics obtained from artificial PD sources as well as the PD in distribution transformers. This paper also provides useful information to design and construct high quality distribution transformers, especially with regards to the time factor for the impregnation process.

\section{Theory}

\subsection{Principle of PD Measurement in HF Range}

The purpose of the PD measurement in the HF range is to investigate the symptom of insulation degradation using capacitive PD coupler to detect the 


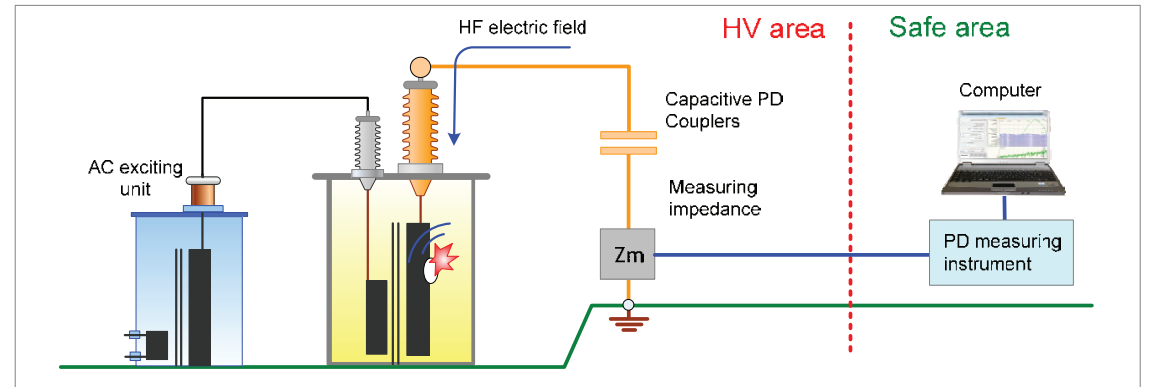

Figure 2 Principle of PD measurement in HF range.

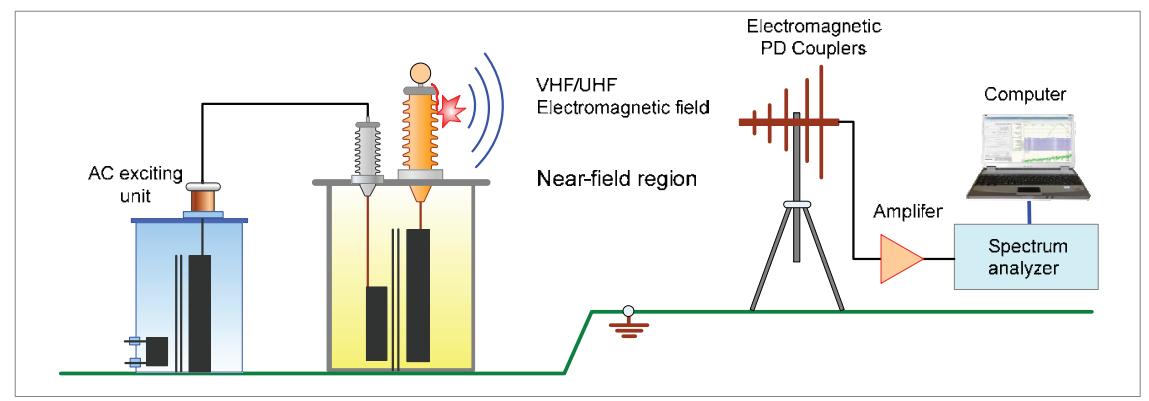

Figure 3 Principle of PD measurement in VHF/UHF range.

electric field component of electromagnetic PD transients occurring at the defect site. The PD activity taking place at the weak spots on the insulation system is evaluated. The PD quantities involved in interpreting the PD activity, which are PD magnitude, PD inception, and extinction voltage (PDIV and PDEV) and PD pattern, are presented to assess the insulation condition of the HV apparatus. The advantage of this technique is well reproducible test results and can be compared with fingerprints established by quality acceptance tests in relevant standards.

\subsection{Principle of PD Measurement in VHF/UHF Range}

In general, external PD occurring on the HV apparatus radiates electromagnetic waves that spread into the surrounding air. For detecting the airborne electromagnetic PD transients, the feasibility of the so-called antenna, operating in the VHF to UHF frequency range, is applied to detect and locate the PD sources in this research for assessment of insulation condition, especially online PD measurements, as illustrated in Figure 3. 


\section{PD Model}

\subsection{Artificial PD Models in Air}

Generally, external PD sources, which are commonly corona discharge and surface discharge, can occur from the sharp edges of both the HV and LV apparatus parts in the air or on surface insulation. To study the physical phenomena of such PD sources, the artificial PD models in the air were designed and constructed, i.e., corona at HV (CHV) side, corona at LV (CLV) side and surface discharge (SF). Figures 4(a) and (b) depict a needle-plane electrode in the air to simulate corona at an HV side and a plane-needle electrode to simulate corona at an LV side, respectively. Figure 4(c) illustrates a spherical and plane electrode separated by an acrylic sheet to produce surface discharge.

\subsection{Artificial PD Models in Oil}

To study the physical phenomena of the PD in an insulating liquid, the artificial PD models in oil were designed and constructed. A tungsten needle with a tip radius of $20 \mu \mathrm{m}$ and a brass plane electrode with a diameter of $45 \mathrm{~mm}$ were used to simulate the corona discharge in oil, as shown in Figures 5(a) and (b). In the case of surface discharge in oil, 10 pieces of impregnated pressboards stuck together as a single insulation were inserted between the $40 \mu \mathrm{m}$ tip radius needle used as the HV electrode and brass plane electrode with the 45-mm diameter used as the grounded electrode, as shown in Figure 5(c). For the internal discharge experiment, the 10 pieces of the non-impregnated pressboards were stuck together as a single insulation placed between the plane electrodes, as shown in Figure 5(d). For preparing the insulating liquid, the mineral oil was dried by oven heating at $60^{\circ} \mathrm{C}$ with 200 mbar for 6 hours. Then, the liquid sample was filled in the test vessel equipped with the electrode system.

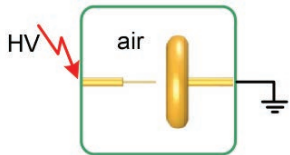

(a) corona at $\mathrm{HV}$

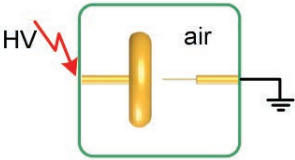

(b) corona at LV

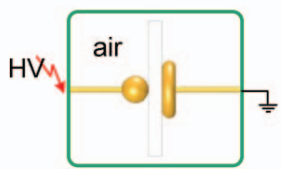

(c) surface discharge

Figure 4 Artificial PD model in insulating air. 


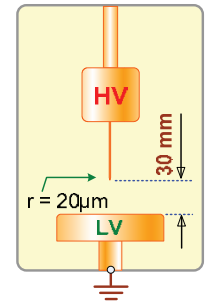

(a) corona at $\mathrm{HV}$

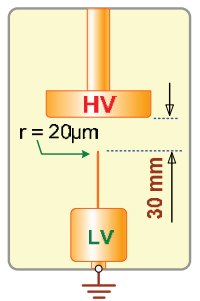

(b) corona at LV

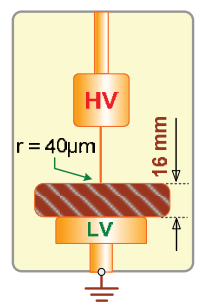

(c) surface discharge

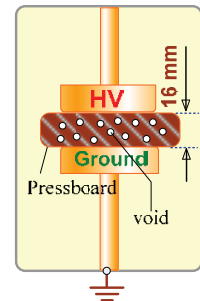

(d) air void discharge

Figure 5 Artificial PD model in oil.

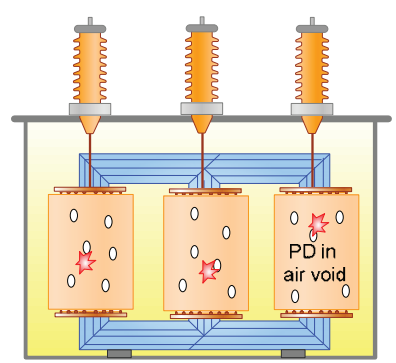

(a) Non-impregnated

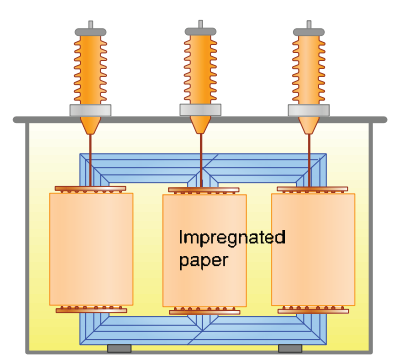

(b) 3,6,9,12 hour impregnated

Figure 6 Non-impregnated and impregnated transformers.

\subsection{PD in Air Void for Transformer Winding Insulation}

To investigate the effect of the impregnation time on the PD characteristics of the liquid-immersed transformers, the investigated transformers were set into the vacuum oven. The temperature in the vacuum was fixed at $65^{\circ} \mathrm{C}$, and the pressure was in control under 5 mbar. The impregnation times were specified for a period of $0,3,6,9$ and 12 hours. The PD experiment was performed after the end of each impregnation period.

Three types of insulating liquids, i.e., uninhibited mineral oil, a commercial natural ester (FR3) and palm oil, olein, including pressboard specimens, were prepared as the insulation of the design and construction transformers. The uninhibited mineral oil ELECTROL(B)-A was sourced commercially from India. FR3 is a commercial natural ester obtained from Singapore, and the palm oil, olein, consisted of $0.1 \% \mathrm{w} / \mathrm{v}$ of Benzotriazole was commercially sourced from a local Thai manufacturer. These liquids were prepared under $60^{\circ} \mathrm{C} 5$ mbar pressure. The basic parameters of these insulating liquid are summarized in Table 1. 
Table 1 Basic electrical characteristics of liquid insulations used for this research

\begin{tabular}{lccc}
\hline Test & Mineral oil & Natural ester & Palm oil \\
\hline Breakdown voltage at $25^{\circ} \mathrm{C}(\mathrm{kV})$ & 65.5 & 67.1 & 72.2 \\
\hline Water content at $25^{\circ} \mathrm{C}(\mathrm{ppm})$ & 17 & 100 & 230 \\
\hline Relative water saturation $(\%)$ & 44.2 & 14.8 & 25.6 \\
\hline $\tan \delta 50 \mathrm{~Hz}$ at 25 and $100^{\circ} \mathrm{C}(\%)$ & $0.19 / 0.3$ & $0.53 / 7.2$ & $1.13 / 10.2$ \\
\hline$\varepsilon \mathrm{r} 50 \mathrm{~Hz}$ at 25 and $100^{\circ} \mathrm{C}(\%)$ & $2.11 / 2.06$ & $3.13 / 2.88$ & $3.14 / 2.9$ \\
\hline IFT $(\mathrm{mN} / \mathrm{m})$ & 49.23 & 43.68 & 34.36 \\
\hline
\end{tabular}

The three identical transformers were constructed with the same processes. After the main component assembly, magnetic core, windings and dielectric liquid, the specified parameters according to IEC 60076 such as turns ratio, copper loss, winding resistance and insulation resistance were measured. Besides, the moisture content of the liquid was measured with the Karl Fischer Coulometer technique after filling the dielectric liquid in the constructing transformer. Then, the constructing transformer was dried in a vacuum oven at $80^{\circ} \mathrm{C}$ and 5 mbar pressure for 6 hours. After that, the moisture content in the paper was measured with the Karl Fischer Coulometer technique.

\section{PD Experimental Setup}

\subsection{PD Measurement in Air}

To capture the signatures from different PD sources without airborne noise due to a radio broadcast, the PD experiment was conducted in a shielding room at the Electric and Electronic Products Testing Center (PTEC) Thailand, as shown in Figure 7 . The electromagnetic wave radiated from the artificial PD models was detected by the log-periodic antenna with measuring bandwidth of $30 \mathrm{MHz}-1 \mathrm{GHz}$ and was analysed by using the spectrum analyser as illustrated in Figure 8.

The PD test procedure in this research can generally be divided into the following steps: At first, the artificial PD model and the HV source were set in the shielding room. Then, the background noise level was measured. After that, the ac voltage was applied to the artificial PD model and gradually the voltage level was increased until the electromagnetic wave radiated from the PD could be detected, and the test voltage was increased until the electromagnetic PD signal was obviously observed and finally the frequency spectrum of the PD signal was recorded. The experiment was performed with all artificial PD models, which led to 60 experiments in total. 


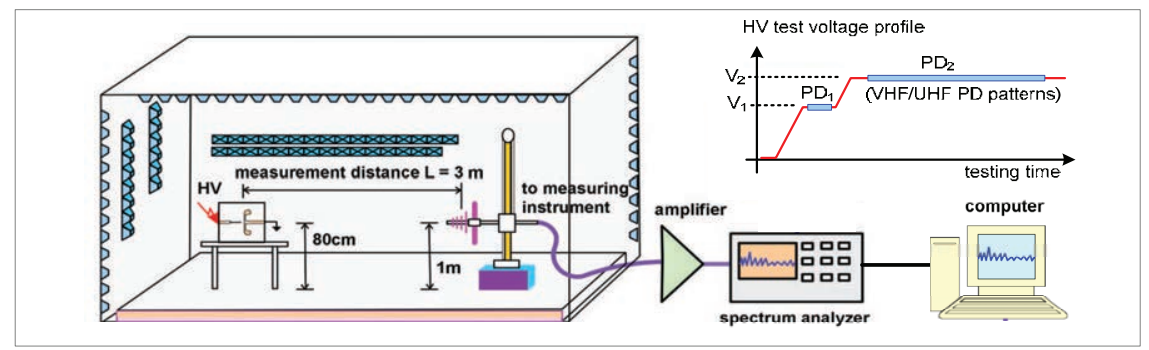

Figure 7 PD in air measuring circuit and test voltage profile.
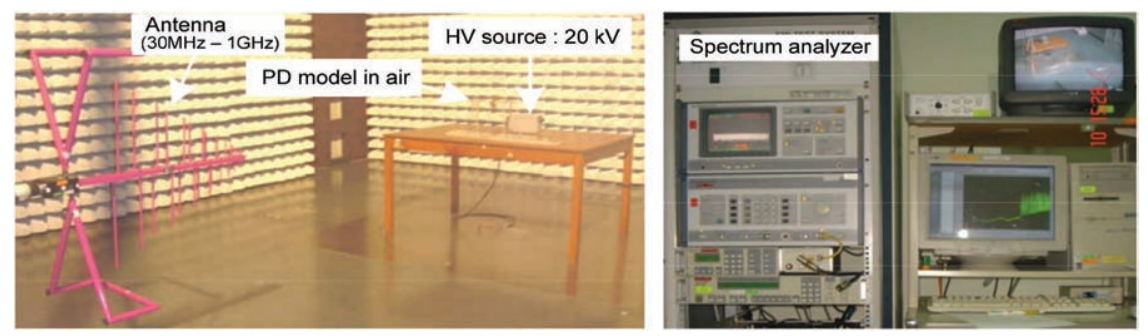

Figure 8 Test arrangement for PD in air measurement and measuring system.

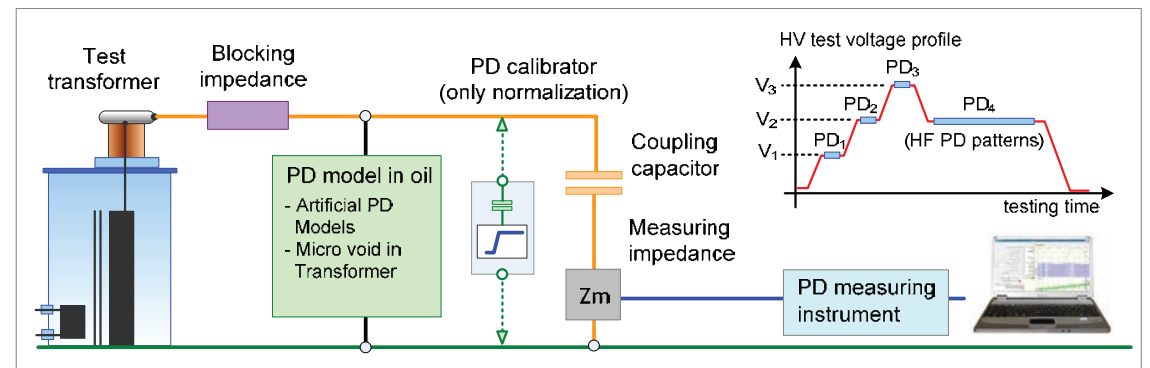

Figure 9 Measuring circuit of PD in oil and transformer and test voltage profile.

\subsection{PD Measurement in Oil and Distribution Transformer}

The measuring circuit for the PD in oil and transformer was conducted in accordance with the IEC 60270, as depicted in Figure 9. The components of the test circuit comprise the test transformer, blocking impedance, PD model, capacitive sensor and measuring instrument. The bandwidth of the PD measuring system was set as wideband having the lower and upper limit frequency of $\mathrm{f}_{1}=30 \mathrm{kHz}$ and $\mathrm{f}_{2}=30 \mathrm{MHz}$, respectively. 

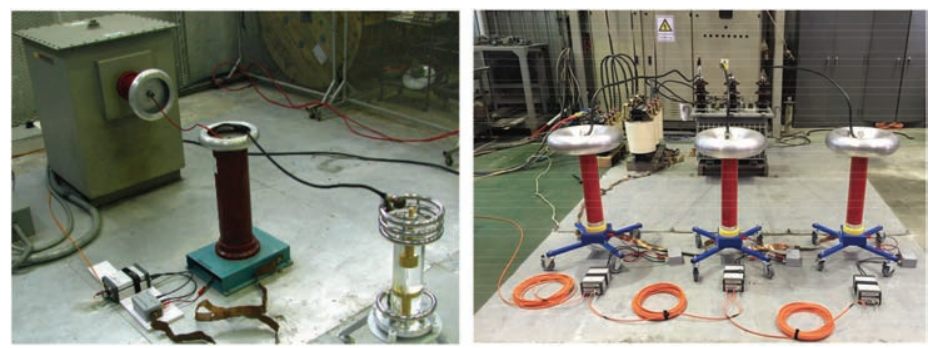

Figure 10 Test arrangement for PD in oil and transformer and measuring system.

The test procedure for performing the PD measurement of this experiment can be divided into the following steps: At first, the measuring circuit was set up, as depicted in Figure 10. Then, the measuring frequency range was adjusted, and the measuring circuit was calibrated with a known standard charge (apparent charge) via the terminals of the test object. Next, the background noise was recorded. After that, a stepped voltage was applied to the PD model with a dwell time on each step of at least $10 \mathrm{~s}$, and the stepped voltage was increased to the enhancement (withstand) level. Then, the stepped voltage was decreased gradually to the rated voltage. Finally, the PD signal was recorded for 1 minute.

\section{PD Measurement Results}

\subsection{PD Measurement Results of Artificial PD Models in Air}

Table 2 shows the frequency spectrum of the captured PD signal in air detected by the antenna in the $\mathrm{VHF} / \mathrm{UHF}$ range.

\subsection{PD Measurement Results of Artificial PD Models in Oil}

Table 3 shows the phase-resolved PD pattern (PRPD pattern) and the frequency spectrum of the captured PD signal in oil detected by the capacitive sensor in the HF range.

\subsection{PD Measurement Results of Air-filled Voids in the Transformer Insulation}

Table 4 shows the PRPD patterns and frequency spectrum of the captured PD signals generated by the air-filled voids inside the non-impregnated paper within the mineral oil-, natural ester- and palm oil-immersed transformers 
Table 2 Frequency spectrum of the captured PD signal in air

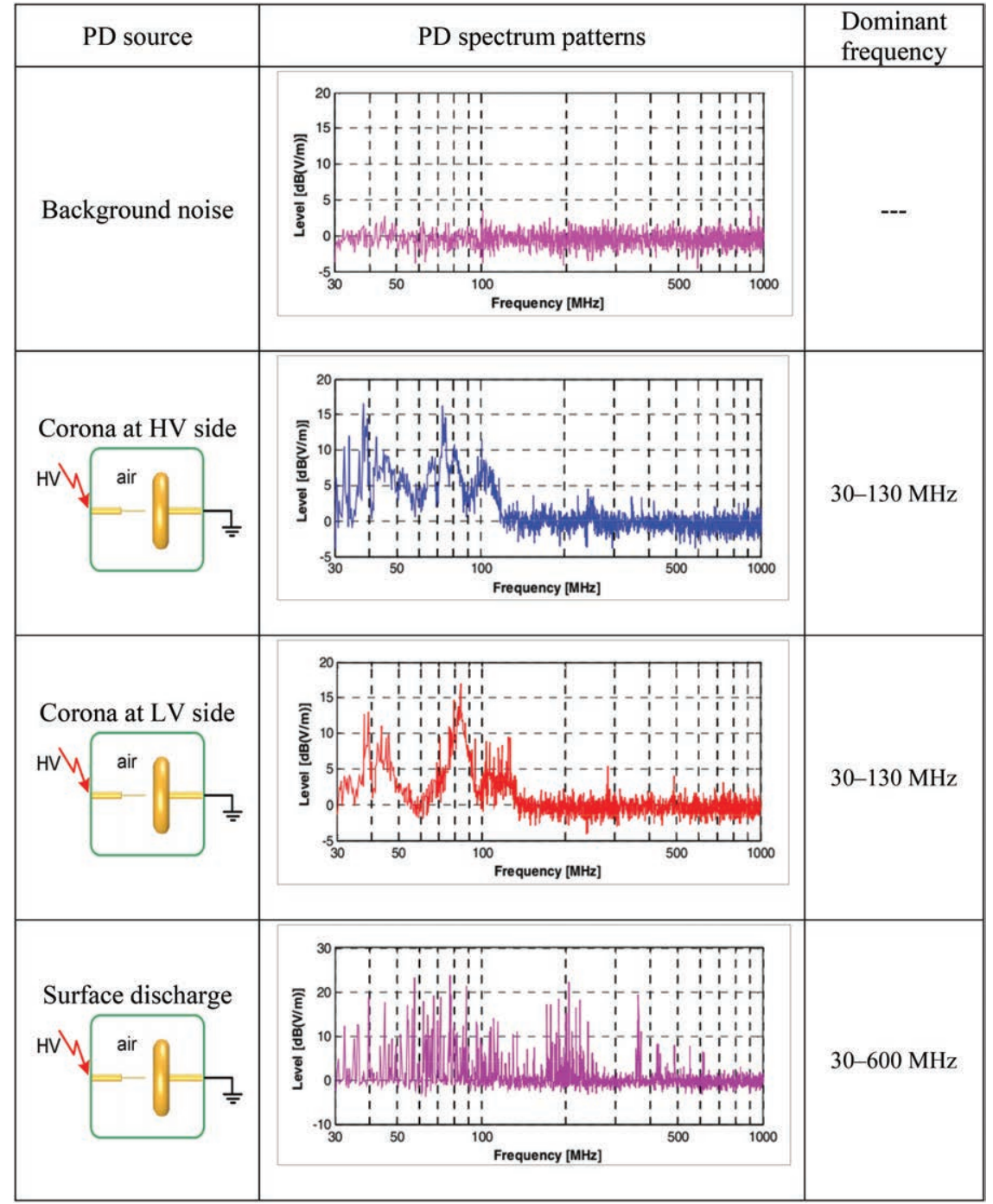

tested at $1.3 \mathrm{U}_{\text {rated }}\left(28.6 \mathrm{kV}_{\mathrm{L}-\mathrm{L}}\right)$ and detected by the capacitive sensor in the HF range.

Tables 5 to 7 show the PRPD patterns and frequency spectrum of the captured PD signals generated by the air-filled voids inside the non-impregnated papers and the 3, 6,9 and 12 hours impregnated papers within the mineral 
Table 3 PRPD pattern and frequency spectrum of the captured PD signal in oil

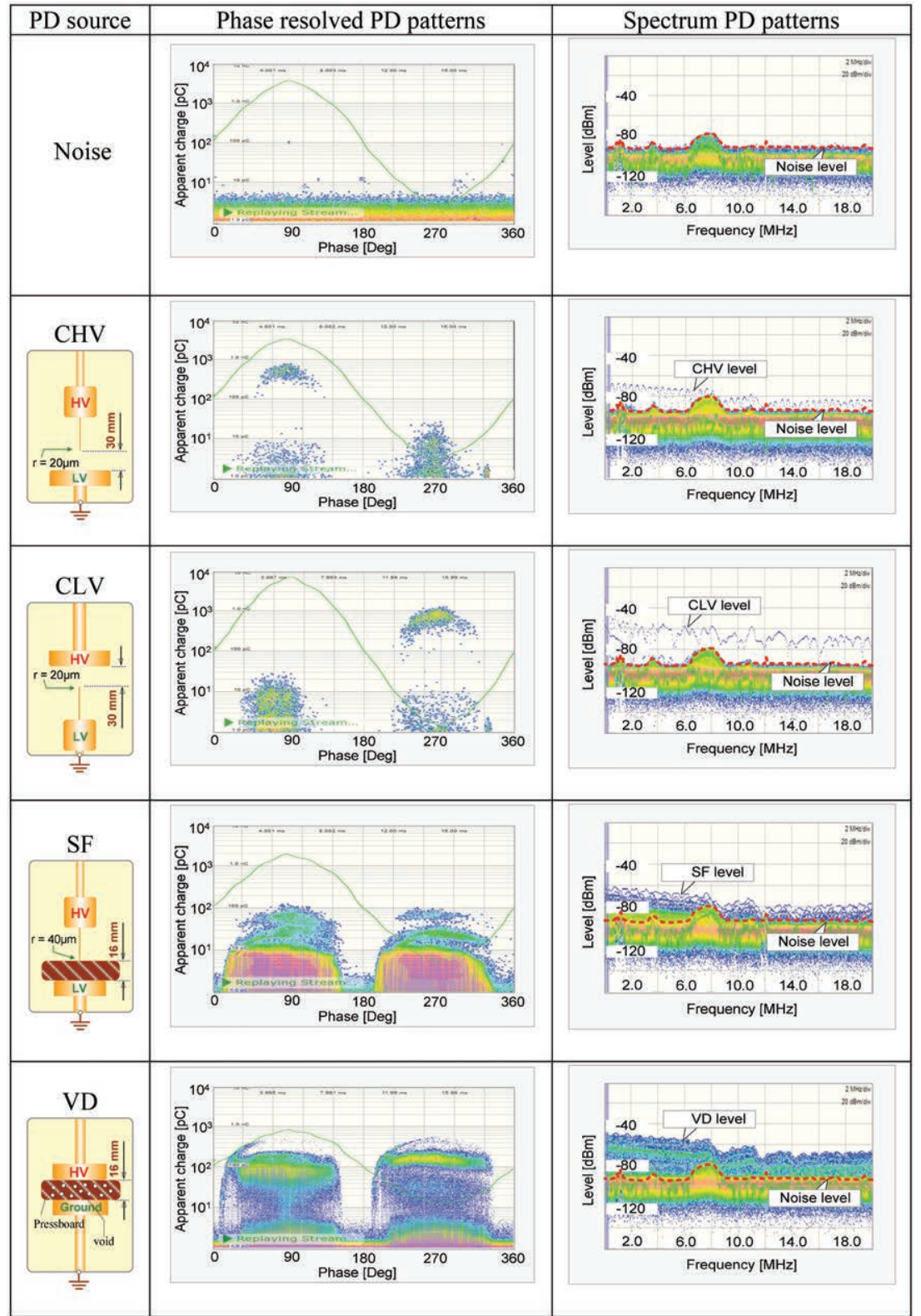

Note: $\mathrm{BN}=$ background noise, $\mathrm{CHV}=$ corona at $\mathrm{HV}$ side, $\mathrm{CLV}=$ corona at $\mathrm{LV}$ side, $\mathrm{SF}=$ surface discharge, $\mathrm{VD}=$ void discharge. 
Table 4 PRPD patterns and frequency spectrum of the PD signals generated by the airfilled voids inside the non-impregnated paper within the mineral oil-, natural ester- and palm oil-immersed transformers

\begin{tabular}{|c|c|c|}
\hline PD source & Phase resolved PD patterns & Spectrum PD patterns \\
\hline Noise & 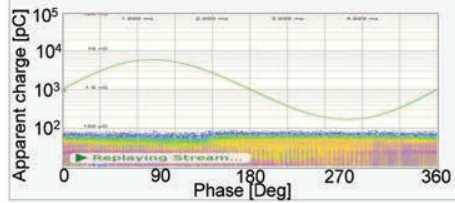 & 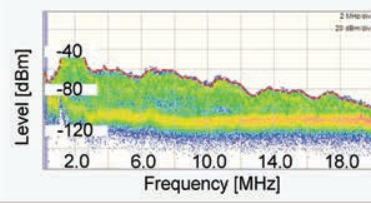 \\
\hline $\begin{array}{l}\text { Mineral oil } \\
\text { transformer }\end{array}$ & 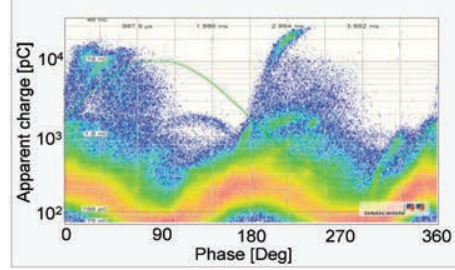 & 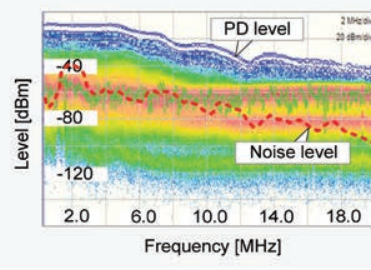 \\
\hline $\begin{array}{c}\text { Ester } \\
\text { transformer }\end{array}$ & 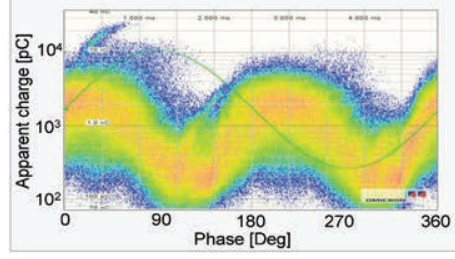 & 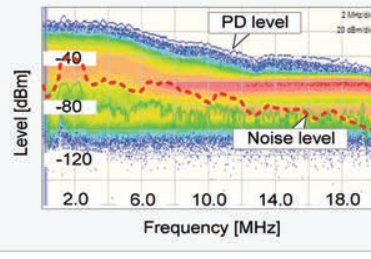 \\
\hline $\begin{array}{l}\text { Palm oil } \\
\text { transformer }\end{array}$ & 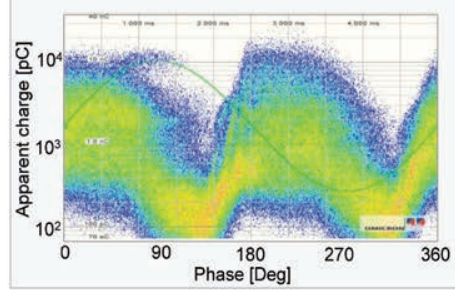 & 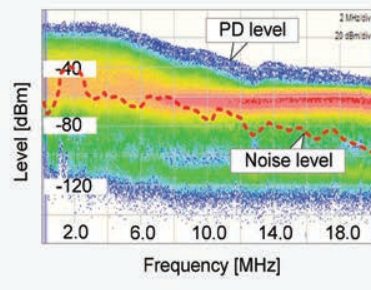 \\
\hline
\end{tabular}

oil-, natural ester- and palm oil-immersed transformers tested at $1.3 \mathrm{U}_{\text {rated }}$ $\left(28.6 \mathrm{kV}_{\mathrm{L}-\mathrm{L}}\right)$. Figure 11 illustrates the comparison of $\mathrm{Q}_{\mathrm{IEC}}$ generated by the air-filled voids inside the non-impregnated papers and the 3, 6, 9 and 12 hours impregnated papers within the mineral oil-, natural ester- and palm oil-immersed transformers. 
Table 5 PRPD patterns and frequency spectrum of the PD signals generated by the air-filled voids inside the non-impregnated papers and the 3, 6, 9 and 12 hours impregnated papers within the mineral oil-immersed transformer

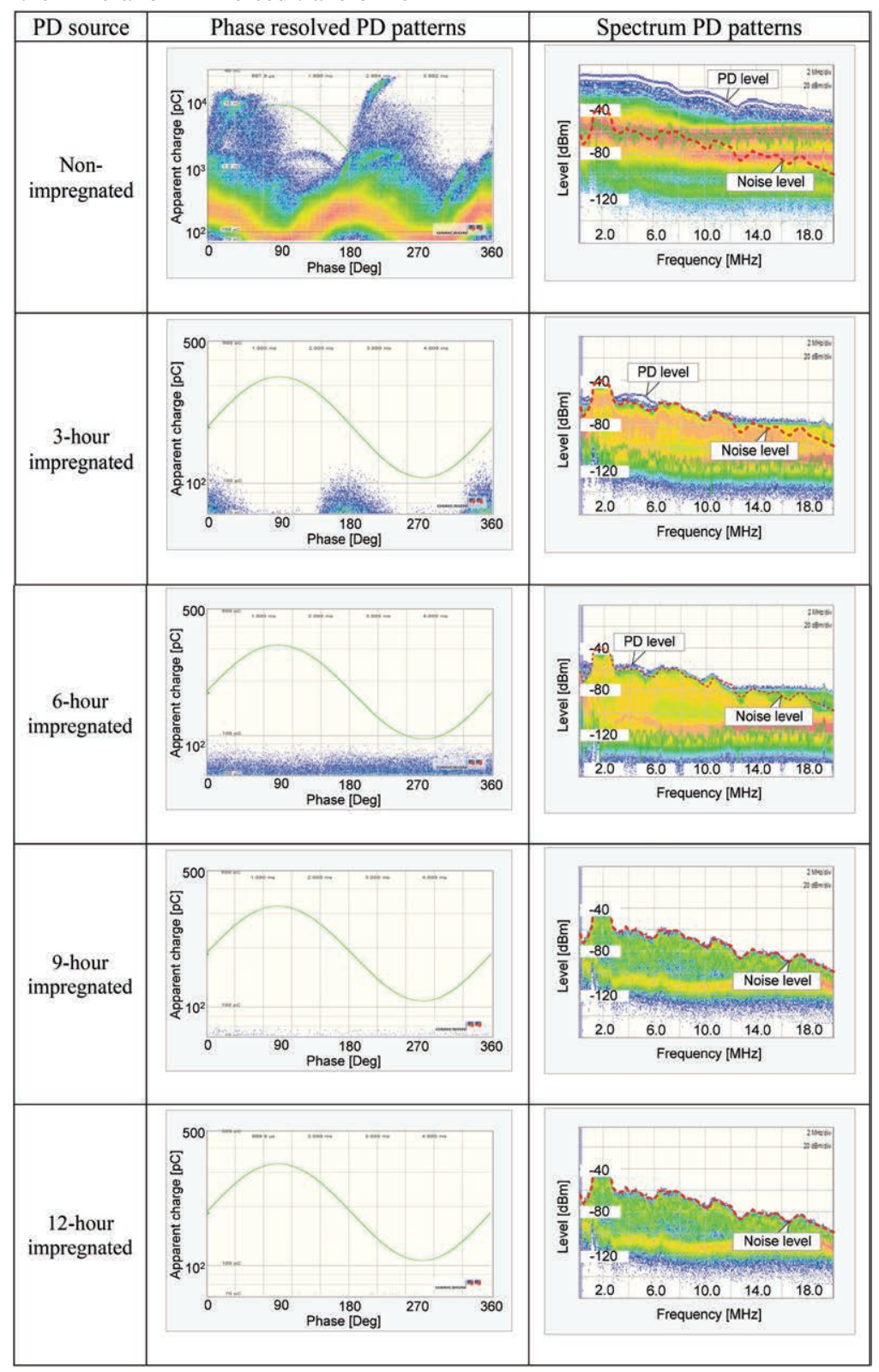


Table 6 PRPD patterns and frequency spectrum of the PD signals generated by the air-filled voids inside the non-impregnated papers and the 3, 6, 9 and 12 hours impregnated papers within the natural ester-immersed transformer

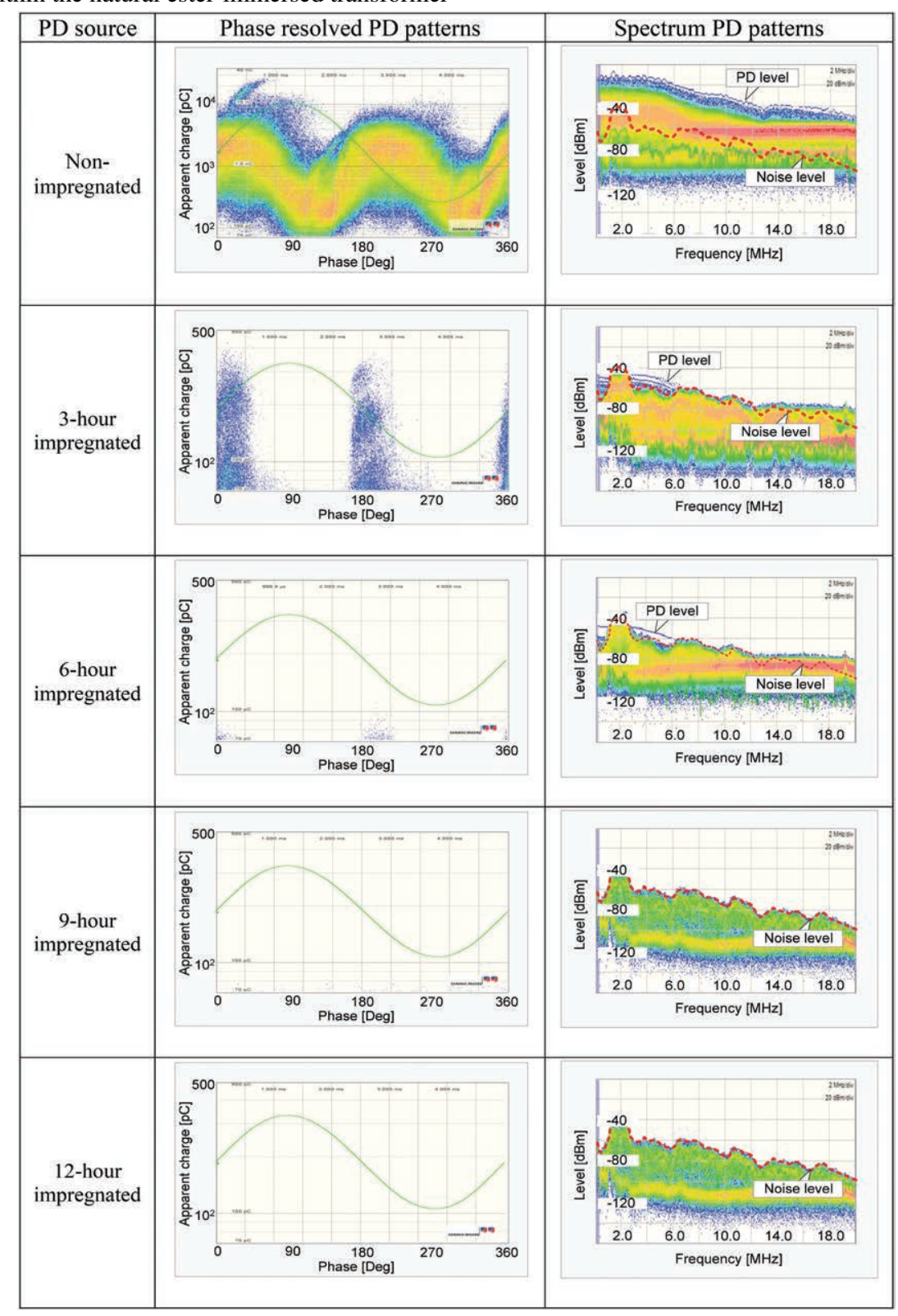


Table 7 PRPD patterns and frequency spectrum of the PD signals generated by the air-filled voids inside the non-impregnated papers and the 3, 6, 9 and 12 hours impregnated papers within the palm oil-immersed transformer

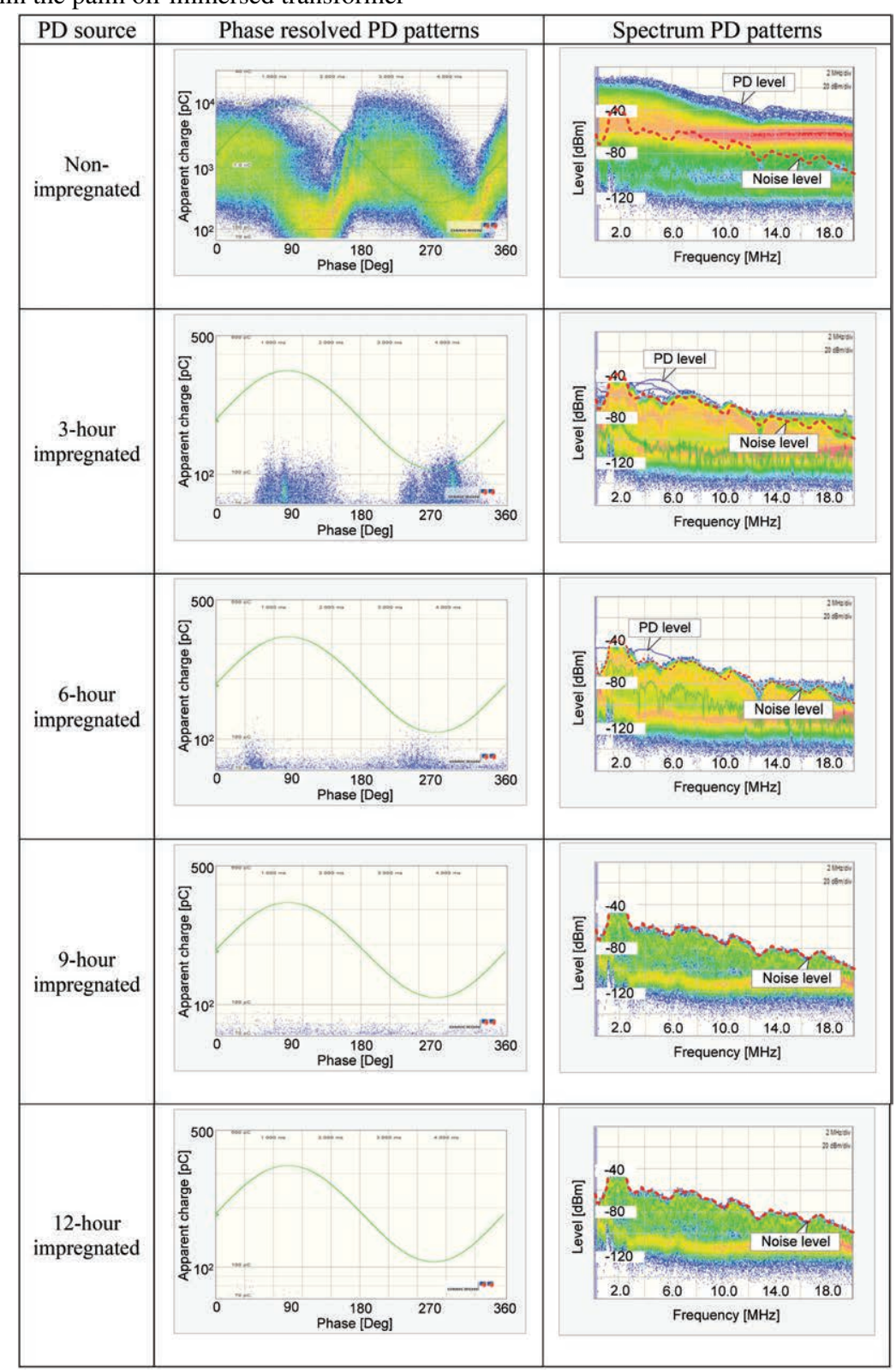




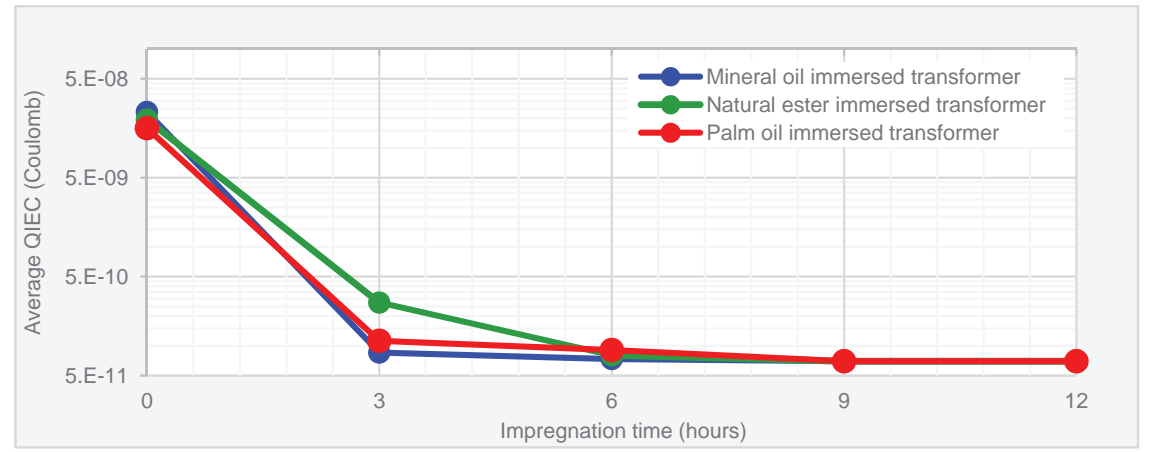

Figure 11 Comparison of Q QIEC generated by the air-filled voids inside the non-impregnated papers and the 3, 6, 9 and 12 hours impregnated papers within the mineral oil-, natural esterand palm oil-immersed transformers.

The PD spectrum shows that it is in the frequency range up to gigahertz. Therefore, both the antenna and communication theories are beneficial and also have high potential to apply in the PD measurement.

\section{Conclusion}

From the experimental results, it can be concluded that the electromagnetic PD transients radiated from the corona discharge of both the HV- and LV sides in the air are in the VHF range, and surface discharge surrounded by the air is extended up to the UHF range. For the PD in an insulating liquid, the PRPD pattern in the HF range is a valuable tool to characterize the PD sources. The PD in air-filled voids inside insulating papers of the mineral oil transformer was obviously different compared with those of the natural ester and the palm oil transformers. For the manufacturing process of distribution transformers as reported in this research, it is found that the 9-hour impregnation duration of the dry insulation paper is suitable for improving the oil-paper insulation with an acceptable PD level. Therefore, it is very clear that the PD can generate noise signals that disturb the communication system. To detect the PD occurring inside the transformers is very important because the PD-generated noises can disturb the communication signal and so on. Moreover, application of the antenna theory, as well as the communication theory, is very useful, and also has high potential to detect the PD sources in the $\mathrm{HV}$ equipment. 


\section{Acknowledgements}

This work was supported by the King Mongkut's Institute of Technology Ladkrabang Research Fund (grant number KREF 046107). The authors also gratefully acknowledge the support by the staff at the Dielectric Analytika Laboratory, KMITL.

\section{References}

[1] Norasage Pattanadech, "Partial discharge inception voltage characteristics of mineral oil", PhD thesis, Graz University of Technology, 2013

[2] T. K. Saha, "Review of modern diagnostic techniques for assessing insulation condition in aged transformers," Dielectrics and Electrical Insulation, IEEE Transactions on, vol. 10, pp. 903-917, 2003.

[3] Z. D.Wang, P.A.Crossley, KJ.Cornick, D.H.Zu, "Partial discharge location in power transformers", Proc. IEE Science, Meas. Tech., Vo1. 147, No. 5, pp. 249-255, 2000.

[4] R.E.James, B.T. Phung and Q.Su, "Application of digital filtering techniques to the determination of partial discharge location in transformers", IEEE Transactions on Electrical Insulation, Vol. 24, No. 4, pp. 657-668, 1989. Vernon Cooray, "An Introduction to Lightning", 2015, Springer

[5] N. Pattanadech, Partial Discharge Inception Voltage Characteristics of Mineral Oil, Dissertation, Graz University of Technology, 2013.

[6] CIGRE Working Group A2.35, Experiences in Service with New Insulating Liquids, CIGRE 436, October 2010.

[7] Pukel, G. J., et al., "Power transformers with environmentally friendly and low flammability ester liquids," CIGRE A2-201, 2012

[8] Martin, D., et al.,"An overview of the suitability of vegetable oil dielectrics for use in large power transformers," Proc. 5th Annual Euro TechCon, Chester, United Kingdom, 2006.

[9] Dolata, B., et al., "New synthetic ester fluid for the insulation of liquid immersed transformers," Conference Record of the 2006 IEEE International Symposium on Electrical Insulation, 2006.

[10] Jinhua, H., et al., "Application of Insulating Camellia Oil in High Fire Resistance Transformer," International Conference on High Voltage Engineering and Application (ICHVE), 2012. 


\section{Biographies}

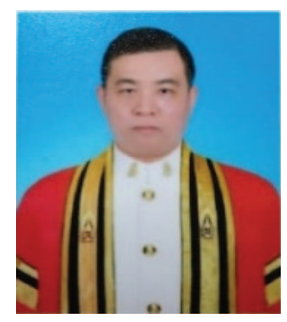

Sakda Maneerot received his M.Eng. degree in electrical engineering from the King Mongkut's Institute of Technology Ladkrabang in 2018. Currently, he pursues his Ph.D at the Electrical Engineering Department, Faculty of Engineering, King Mongkut's Institute of Technology Ladkrabang, Bangkok, Thailand. His research activities have been mainly involved with liquid dielectric characteristics and transformer design and testing.

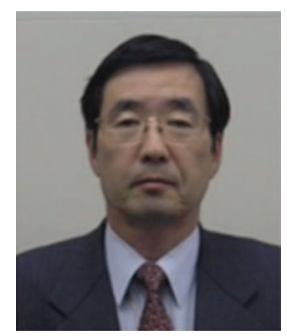

Masaaki Kando (Fellow IEEJ, Life member IEEE) graduated from the Tokai University, Japan with M.Eng. degree in 1973. He joined the academic staff as an assistant professor of the Department of Electrical Engineering, Tokai University in 1973, lecturer in 1978, associate professor in 1985 and professor in 1992. He was awarded the Doctor of Engineer degree by the Nagoya University in 1991. He received his professor emeritus title from the Tokai University in 2011, has been an IEEE Life Member, IEEJ Fellow and IEEJ Life Member since 2014. He has supported the Malaysia - Japan Higher Education Program as an expert and lecturer under the Malaysian Government, and other Asian universities (Thailand, Cambodia and Laos) in high-voltage engineering. Currently, he is a visiting professor of the KMITL in Thailand. 


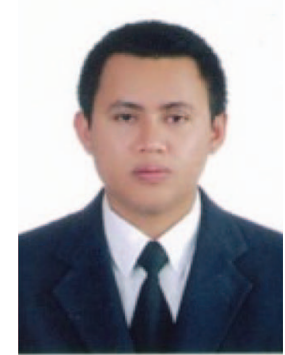

Norasage Pattanadech received his B.Eng and M.Eng degrees in electrical engineering from the King Mongkut's Institute of Technology Ladkrabang in 1998 and the Chulalongkom University, Thailand in 2002, respectively. He was also awarded his Ph.D. degree by the Institute of High Voltage Engineering and System Management, Graz University of Technology, Austria in 2013. Currently, he works as an associate professor at the King Mongkut's Institute of Technology Ladkrabang, Bangkok, Thailand. His research activities have been mainly involved with partial discharge in insulating liquid, solid insulator characteristics and high-voltage testing. 
